\title{
Review of Geospatial Approaches to the Anthropological Sciences by Sarah Robinson
}

Sarah Robinson ${ }^{1,2}$

\author{
Book details \\ Edited by Robert L Anemone and Glen C. Conroy \\ Geospatial Approaches to the Anthropological Sciences. \\ School for Advanced Research Press/University of New Mexico Press, 2018. \\ 304 pages, ISBN: 978-082635967
}

Keywords: Anthropology, Archaeology, Geographic information systems, Remote sensing

This book reviews approaches and methods in geospatial analysis for anthropological applications. The subject matter focusses mostly on archaeological and paleoanthropological applications, including two chapters on ancient pastoral societies.

For anthropologists presented with spatial questions, the second chapter (Emerson and Anemone) is particularly useful and presents the basic concepts of spatial analysis and characteristics of geographic information systems (GIS) in which surfaces and objects can be represented in a number of different ways. Remote sensing systems generating data on the earth's surface according to its optical and thermal properties, or surface slope and aspect (digital elevation models), are presented with different applications. A number of large open access datasets are included, and the characteristics of different platforms (including aeroplanes, satellites and drones) are explained with considerations such as spatial, spectral and temporal resolution. Different imaging techniques are also discussed: for example, most sensors conduct 'passive' observation of optical and thermal surface properties, whilst 'active' LiDAR (light radar) technology measures distance to a target by sending pulses of laser light. Differences in return times and wavelengths are then used to make 3-D representations of the target. These techniques are all used in the chapters which follow.

\footnotetext{
Correspondence: sarah.robinson09@gmail.com

${ }^{1}$ Visiting Researcher," Department of Zoology, University of Oxford, Zoology

Research and Administration Building, 11a Mansfield Rd, Oxford OX1 3SZ, UK
}

${ }^{2}$ La Cousteille, 09400 Saurat, France

Perhaps the most interesting chapter for pastoralist applications is Chapter 8 (Vining and Burns) which discusses ecological decision-making of Andean pastoralists using geospatial agent-based models. The study looks at the drivers of change in the distribution of alpaca herders from an agglomerated pattern to a more dispersed pattern of habitation, coinciding with the development of the Tiwinaku state in 500-1100 CE. The authors hypothesise that the emergence of the state stimulated intensification of alpaca production from a subsistence level to more commercial production in response to new economic demands. They construct agent-based models in which changing economic motivations over time are associated with different optimal herd size and reproduction rate levels. These result in the establishment of new herding settlements whose location was determined by ecological niche criteria defined by known habitat suitability for alpaca herding. These include factors such as altitude, slope and aspect, water availability and vegetation type and density. Table 8.1 is a particularly useful example of how different sources of remote sensing data can be used to generate these environmental factors which can then be combined to create a habitat or niche suitability surface used to predict where pastoralists will relocate according to their new optimisation criteria. The model reproduces almost exactly the changing distribution of settlements as actually observed in the archaeological evidence and thus supports the hypothesised explanation, replicating the transformation of an Andean herding society and colonisation of new ecological niches. 
The other paper which focusses on pastoralists is by Frachetti, Smith and Copp (Chapter 9) and focusses on the impact of small mobile societies on the development of settlements in Inner Asia including much of the ancient Silk Road areas between Central Asia, western Mongolia, Xinjiang and northern Pakistan. The authors hypothesise that the pathways and trajectories of herders are determined by the availability and quality of pasture resources, distributed seasonally and attitudinally across the study zone. They apply a spatial hydrological modelling tool which simulates the movement of herds of livestock across a cost surface whose cells are classified according to measures of vegetation quality. Two datasets were produced, one with random winter settlements generated according to elevation, and another corresponding to a cost surface based on remotely sensed indices of vegetation productivity. The distance between highland pasture and lowland settlement points is weighted by the benefit of passing over rich pasture. Like water, the simulated trajectories of animals follow the path of richest pasture between the highland and lowland areas. Flows accumulate according to grass quality and run towards the corresponding iteration of randomised settlements. After running for many iterations, the model produces dominant regional flows-many of which correspond to vectors towards historically known centres of trade such as Gilgit, Tashkorgan and Herat.

The rest of the book does not cover pastoralist themes, but the case studies illustrate important principles of geospatial applications. Chapter 4 (Conroy et al.) describes the use of unsupervised image classification to identify the spectral signature associated with fossil presence. Such signatures can help archaeologists identify new sites with a high likelihood of yielding successful finds during ground searches, reducing field costs.

The use of very high-resolution imagery collected from drones to classify different types of forest area using object-based imagery analysis is discussed in Chapter 7 (Wich et al.). Here, patterns associated with objects, in this case trees, are identified in order to classify forest areas into different types. This case illustrates how patterns in the landscape, rather than the spectral characteristics of pixels more commonly used in image classification, can be employed to map different types of land use.

Hlusko (Chapter 3) looks at the history of remote sensing in African palaeoanthropology, mapping existing sites or looking for new potential fossil-bearing deposits using aerial photography, Landsat and modern high-resolution Ikonos imagery. Other applications of GIS science in archaeology and palaeoanthropology are outlined in a number of chapters, including three-dimensional modelling of outcrops corresponding to fossil locations using LiDAR (Anemone et al., Chapter 5) and the use of geospatial methods to describe and classify the morphology of tooth shape and wear in relation to diets, treating tooth surfaces as landscapes amenable to this type of analysis (Ungar, Chapter 6). Chapter 10 (Williams et al.) assesses the potential of ground-based LiDAR combined with drone-based photography and thermography for architectural analysis of buried structures and creation of landscape models of ancient irrigated fields.

Other than the Vining and Burns paper, the book does not go into detail on the spatial methods often used to model decision-making in pastoral societies, such as construction of models to explain and predict grazing movements based on spatially distributed predictor variables. For such applications, texts on movement and habitat selection, often from the discipline of ecology, may be more appropriate. However, the book does present a diverse range of applications, in particular from the field of archeology, and will be useful for those interested in geospatial approaches to the study of human societies in space and time.

Abbreviations

GIS: Geographic Information Systems; LiDAR: Light radar

Acknowledgements

Not applicable

Author's contributions

The author read and approved the final manuscript.

Funding

Not applicable

Availability of data and materials

Not applicable

Ethics approval and consent to participate

Not applicable

Consent for publication

Not applicable

Competing interests

The author declares that she has no competing interests.

Received: 5 June 2019 Accepted: 7 June 2019

Published online: 02 August 2019

\section{Publisher's Note}

Springer Nature remains neutral with regard to jurisdictional claims in published maps and institutional affiliations. 